\title{
The Application of Online Check-in in the Process of Passenger Handling in Air Transportation
}

\section{František Adamčík ${ }^{1}$, Jozef Galanda ${ }^{2}$, Edina Jenčová ${ }^{2}$, Radoslav Šulej $^{2 *}$}

\footnotetext{
${ }^{1}$ Department of Avionics, Faculty of Aeronautics, Technical University of Košice, Košice, Slovak Republic

${ }^{2}$ Department of Air Transport Management, Faculty of Aeronautics, Technical University of Košice, Košice, Slovak Republic

*Corresponding author: Technical University of Košice, Faculty of Aeronautics, Department of Air Transport Management, Rampova 7, 04121 Kosice, Slovak Republic, Email: radoslav.sulej@tuke.sk
}

\begin{abstract}
Passenger handling is one of the most important activities any passenger is obliged to carry out prior to boarding the plane to depart. For the handling process to be safeguarded, it is inevitable to perform the services involved in it fast and efficiently so as to prevent idle times or delays during the procedures potentially resulting in delay of flight. By gradual development of the so-called web-based information technologies, some of the activities involved in the handling process can be delegated to the passengers themselves, thereby achieving a faster course of the passenger handling process. In this contribution the authors are dealing with the status quo of the on-line web-based check-in process in air transportation forecasting the expected course of events in these services in the future. Next, based on analyzing functions and characteristics of similar solutions available in the market, the authors are putting forward their new proposal of their own design of a self-service, on-line system of passenger handling with the aim to simplify and expedite the entire handling process. It is the aim of the authors to develop a competitive design in terms of costs as well as new function and services not offered by the hitherto existing with emphasis on improving efficiency of passenger handling at the airports. The resulting solution thanks to internet based technologies is platform independent and fully applicable to the process of airport passenger handling. To an equal extent, the solutions are being applied by the authors to the educational process, as a training tool for the preparation of the aviation personnel and also as part of simulation models for research in the field of airport processes optimization.
\end{abstract}

Keywords

DCS - Online check-in - Passenger handling - Self Check-in - Web check-in 


\section{Introduction}

Passenger handling is one of the most important activities any passenger is obliged to carry out before departure. Over the resent years, the usual form of handling at counters is declining to the benefit of moder, self-service processes, particularly self-service kiosks, mobile-based chek-ins or online check-in in via the Internet. It is the last of the mentioned, online check-in that is currently gaining the upper hand at air carriers (see Fig. 1) to make it easier for the passengers to be handled for their flights. At the same time, this system is also reducing the transportation costs both for the airliners and airports as well. They are employed not only by the low-cost carriers but increasingly by those, vintage airlines. Travelers are glad to have been provided comprehensive handling services (enabling for them to chose their seats in the aircraft and decide the time of when to undergo the handling process) in the comfort of their homes and with no need to waste their time at the airports. The very advantage in saving time spent at the airport, as a passenger with no baggage can be directly admitted to the departure gate as there is no need for waiting in a queue for check-in. Consequently they can spend their time more pleasantly e.g. in shopping zones thereby contributing to the revenues oaf the airport operators. From the global point the passengers can be under the positive impression as regards the air carrier providing such services [1].

Currently, air transportation is facing fierce competition in all aspects. Consequently every air carrier is striving to offer their clients the best possible services including online handling, but this is why each of the online system works differently depending on the airlines providing them. The differences consist in the functions offered, scale of the baggage handling even in the handling process itself in terms of the entry parameter, seat selection or fees charged for the various sort of services. Diversity in the services can often be taken into consideration on the part of the traveler when deciding for the air carrier.

\section{The Online Handling Process}

The Online check-in is a system designed to handle passengers by way of communicating in via a web interface. The web-based (online) check-in provided by air carriers is both fast and simple. It enables reservation of a chosen seat, printing out one's own board-ticket whether from the comfort of their homes, office or elsewhere. The online Boarding-pass is an excellent way of saving time for passengers. Carrying only a hand-baggage they can can pass directly to the safety checks presenting their board-tickets, ID cards or passports and only the to be admitted to their departure gates. Travelers with

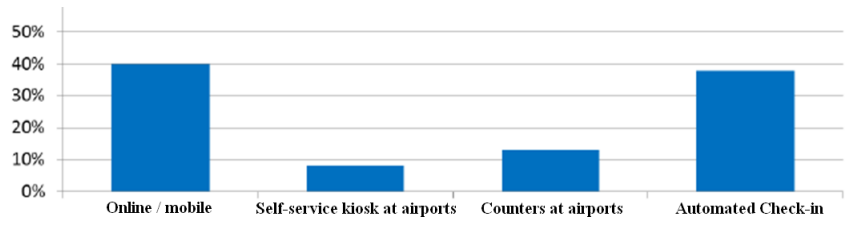

Figure 1. Preferred methjod of passenger handling

hold baggage can leave them on the stacking shelves for baggage in the terminal building.

If the air carrier is providing online passenger handling, a certain sequence of steps is to be observed. Having made the reservation, the passenger will be advised of the moment when the online check-in for the appropriate flight turns open either in the form of confirmation e-mail at the flight reservation with the air carrier or in via web pages of the travel agency so as to perform chek-in as soon as possible. Some of the air carriers have even started offering automated check-in directly at the reservation stage. Others are currently offering mobile applications advising the traveler on the important deadlines, updating reservation and, if need be, alerting them to any changes or flight delays. It also enable making new reservations or finding details of the distance covered. Vintage air carriers such as the British Airways even advise on the time when the appropriate gates are activated, thereby leaving more timer for having a rest prior to flight instead of continuous monitoring the table of departures. EasyJet provides a mobile-based application as accompanying the traveler in the airport lounge. In case when the online check-in turns open at a later time, the air carrier is subsequently advising the passenger on the fact in via an e-mail, SMS or mobile application [2].

Time of handling varies form air carrier to air carrier. Some enable advance handling as much as 28 days (easyJet a Monarch) or just 24 hours prior to the flight e.g. the British Airways. Every air carrier is apt to gather information on the travelers (Advance Passenger Information - API) for their reservation while observing strict rules of security. Passengers are required to present passports and details on insurance depending on the destination and also contact information with addresses of their intended accommodation. Airlines may demand provision of the information as above in advance and online so as to save time at the airport. To activate the check-in process, a booking reference is to be at hand. Most air carriers enable online check-in of as much as nine people. Children up to two years of age can be handled directly at the airport. Again, for further information, it is advisable to check for the web sites of the appropriate air carrier.

In the next phase, he or she can chose or change seating if having decided to pay for the place in question. Further i tis necessary to confirm the number of baggage and, if need be, pay for the excess baggage. Usually, it 
is less expensive to do so in advance and online than directly at the airport. Passengers chosing their seat online are offered better availability of the seats as those making their choice traditionally, i.g. when already at the airport. Some airlines enable their passengers to print their Boarding-pass already of the home. Others make it possible to send the Boarding-pass to an e-mail address, mobile phone or collect it right at the airport. The mobile-phone -based method appears to be the most suitable as the board ticket in the mobile phone is always ready when needed by the traveler. Families or groups of people traveling together may call in all the board-tickets into one mobile phone or several devices as well. In case when the traveler fails to arrange for online check-in, or cannot present it, he or she will either be allowed to receive a new printout of the board-ticket or will be obliged to undergo a classical way of handling at the airport.

Considering any of the online check-in systems, each of them has its advantages and disadvantages. Having made a sound account and survey of the status quo in the field of online systems, our prior goal was to design and develop a possibly to most complex online system that would integrate all the most important and most necessary function facilitating the en tire process of handling. Included in this paper are all the basic functions of classical online check-ins, however, completed by new ones, i.e. those hitherto not offered by the rest of air carriers, or, if so, to a limited extent only (baggage selection- plus excess baggage, additional services, option of immobile passenger etc.). We have focused on this system also with the intention of integrating it either as a whole or only its competitive part into a Local Departure System newly developed at the Faculty of Aeronautics within the framework of the APVV Project under the name of "New generation of departure control system for airports".

\section{Design of Online Web Check-in System}

For us to be able to build on, it was necessary to screen the services already provided by other air carriers. To begin with, we have chosen three airlines from three different countries (Ireland, Germany and USA). To be precise, one of them the Ryanair, the largest low-cost carrier, the next two are national air carriers, namely the Lufthansa and the American Airlines known for different procedures applied to online check-ins (see Fig. 2). Each of the air carriers provide a web-page based on online check-in. When opening the page, it can be seen that in every case there appears an introductory screen, where, on entering the initial data (usually name and surname, e-mail, number of reservation) the traveler entering the system can start the check-in process as it. Access data differ with airlines, the more entry data are available in the initial screen the faster the filtration of the results.

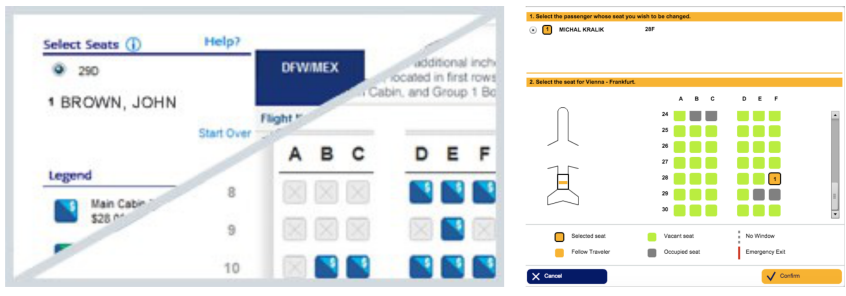

Figure 2. Choosing a seat in an airplane by American Airlines (on left) and Lufthansa (on right)

Following a successful along in there comes to the option of traveler's check-in, where even a group of people can be selected (usually 9 passengers). Each passenger is obliged to produce personal data (nationality, date of birth, type of document, place of issuance, date of validity). Further to follow are the details of the journey (flying from-to, date of flight, number and class of flight, gate number) so as the he or she can verify if the check-in is being made for the appropriate flight. Next comes the choice of seating aboard the airplane, making changes to it or buying and extra seat for greater comfort. Each carrier is offering a different graphical environment for this step. On selecting a seat, some airlines enable choice of the baggage the passenger is wishing to travel with. Baggage is limited for every passenger, but against extra payment it can be extended. Choice of additional services is also available, for extra charges, of course. Some of the carriers offer insurance or special care for pregnant women. As part of offering a general view, the last but one step provides details of the journey and personal information. The last step involves transferring the Boarding-pass to the e-mail address, mobile phone or having it printed out of the home or reprinted if having it lost. Based on the review of these resources, we have found out that all the air carriers are offering equal solution or function, but, ultimately all of them operate on a similar system, having found no big differences among the functions offered. Whereas the steps required by the air carriers follow different order, however, all of them serve the purpose in the same way.

When designing a system, we have taken into account the best function of the existing system trying to integrate them into our system, the main functions of which are as follows:

- Higher number of input data for more simple filtration fo the results

- Option of adding personal data in case of traveling outside the Shengens area

- Presenting information regarding the flight (flying from - to, number of reservation, number of flight, date of departure, arrival etc.)

- Presenting and mandatory confirmation of flight condition and restricted items not to be contained in the baggage 
- Presenting the state of passengers handled, passenger status

- Handling individual or group of passengers, option for immobile passengers

- Options for additional services

- Choosing seats or automated allocation of seats for free

- Baggage options (classical, special sort of baggage - extra such as bikes, ski, tenis equipment, music Instruments, children's accessories, ... )

- Generating a Boarding-pass

- „Re-print“ or repeated printing a Boarding-pass

- Option for retroactive correction of the data already entered Option for sending the Boarding-pass (to the e-mail, mobile or direct printout)

- Alerting to errors, push-button of „Back“ in the individual steps

- Multi-language system

As a basis for proper functioning of the web check-in, it was necessary to develop a fundamental algorithm of the entire online process that which reflect the standard handling process as performed at the airport. The first step in the whole algorithm is entering the initial data (surname, or e-mail, number of reservation, departure and arrival destination). Every traveler has its own data. If he or she enters improper data (i.e. date not complying with the data already stored in the database), the system cannot allow for him or her to step further and the data are required anew. On entering proper data, the flight conditions are presented (in terms of baggage security and of the check-in conditions), the traveler is to agree with them if he or she wants to proceed further.

In the next step details of the flight are presented (number of reservation, number of flight, route, date and time) so that the passenger can acknowledge whether his or her flight data are correct or incorrect. Then it comes to the step when the check-in option is offered to the passenger. At least one passenger is to be chosen for the process to continue, whereas the next process is verifying if all the mandatory data for each passengers have been entered. If everything is all right, it steps further to additional services, where each of the passengers can select for some of the extra services offered by the air carrier (ordering a limousine, taxi, hiring a VIP lounge, guarantee for exact time of arrival). Selection of the services is followed by the option of choosing a seat either individually or being allocated automatically. Then follows the selection of baggage the traveler is wishing to fly with (classical and extra baggage - bike, ski, tennis equipment, music instruments and and children's accessories). After downloading the parameters, the next step is a summary of all the data having entered by the passenger, and when confirmed, it comes to the last steps, namely sending or printing out the board ticket. The algorithm itself is illustrated in figure 3 .

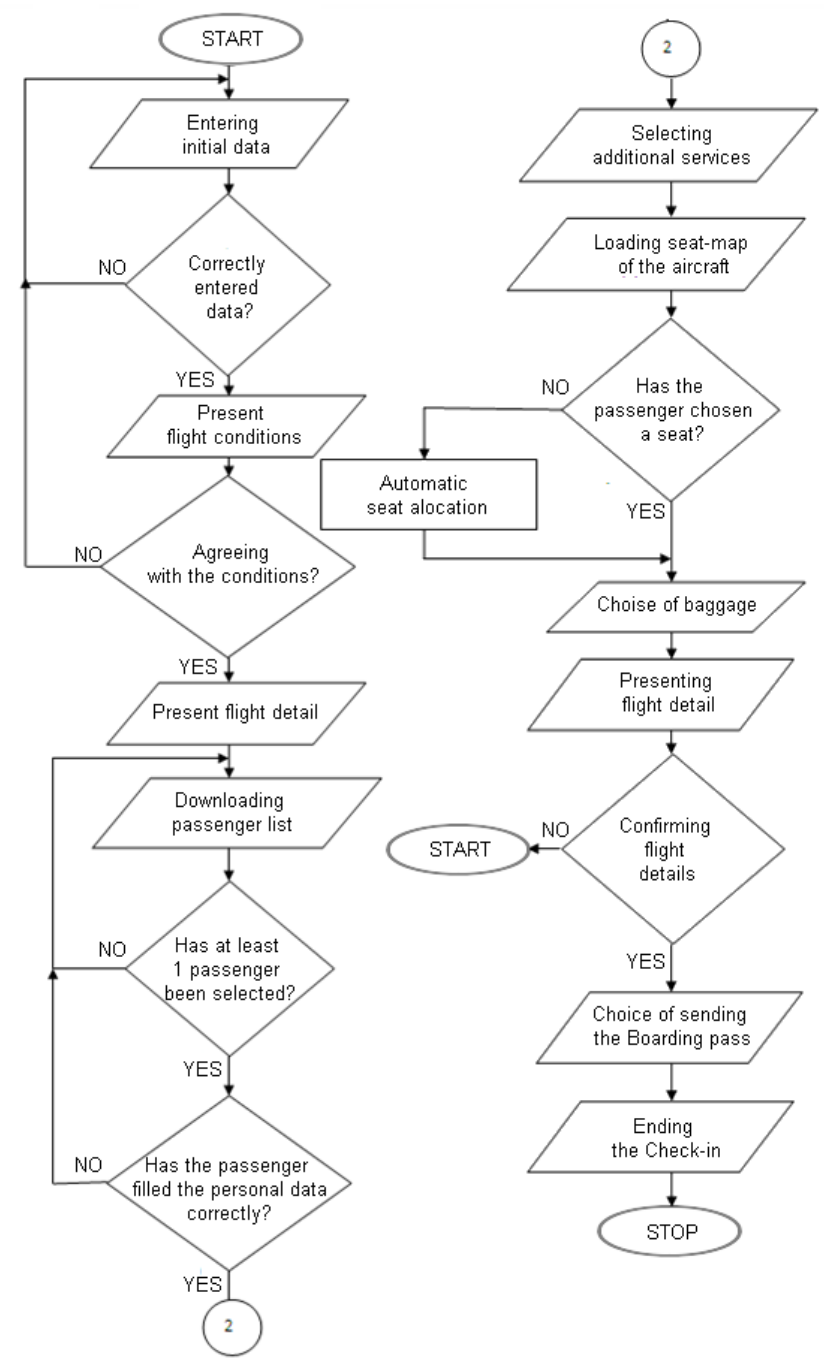

Figure 3. The principle algorithm of solving the online check-in process

In the same way, this algorithm forms the basis for a data-base model, which shows the logical structure of the database, including the relations and links that determine how the da can be stored, accessed, organized and manipulated. The structure depend on the natural organization of the application data and the requirements of the given application.

The elementary precondition to system development was making use of open-source standards of developmental and application environments. For this reason, we have designed the system as a whole on the LAMP environment (Linux - Apache - MySQL - PHP) - set s of tools used for the development of dynamic web pages, which generate the contents for each of the users separately on the basis of input values or variables. The Dynamics of the check-in is developed mainly in a scripting language known as the PHP. I tis very popular and can be run on all known operational systems. To design a system 
further marking languages were necessary, on the bases of which the system design has been developed (HTML, CSS). To activate the system or its effects, a scripting program language the Javascript and its famous library the jQuery were used. All the data the system is working with are stored in the MySQL database server.

\section{System Implementation and the Results Obtained}

On completion of the algorithm and the database model, in which the entities necessary for running the system were created, we could step further the the very process of implementation of the online check-in itself. The result is a dynamic web page, the contents of which is generated on the basis of user (traveler) inputs. Contained in the page are 10 sub-pages or steps, the user have to go through so as to correctly complete the online check-in as a whole. Further development of the rest of the subpages was conducted on the basis of flow-charts on the conditions and details of flight, where implementation of these sub-pages has not been complicated. The subpage where the traveler performing an online check-in required more detailed attention, as it was necessary program the options for passengers, their choice whether they are mobile or immobile, whether all the necessary personal data have been entered by them, and if at least one passenger has been selected for the check-in [3].

Choosing the seats for passenger has been the most complicated part of the implementation, but under a properly chose programming procedure it works without problems. After completing this part, we went further to develop baggage selection. In the next sub-page, we have downloaded the data from the database, which then presented the flight details in total, which have only to be confirmed by the passenger, while in the next step we performed programming of ho the board -ticket is generated. Here, it was necessary to pay primary attention to the graphical design. Then we just went on to program the option of sending the Boarding-pass or its printing as well as the final screen indicating the successful completion of the check-in procedure. After creating the core and the functions of the system, we have started develop the graphical design of sub-pages. The program development of the online check-in is relatively extensive in terms of codes. The entire system is programmed on more than 5000 lines of the source code.

As it can be see in figure. 4, after the system is initialized we take into consideration that the passenger has already registered for the flight and has all the data necessary for performing the check-in. Here, the passenger must enter the data he or she has obtained when having been registered for the flight. Among the initial data are the surname or the e-mail of the traveler, places of departure and destination and the number of reservation. In case when wrong data have been entered, the system will alert the passenger. Subsequently, it is necessary to confirm the conditions of flight (see Fig. 4). After giving his approval to all the conditions, as part of the next step, he or she will be presented details of the flight and the passenger is again obliged to check the data for accuracy. Following this check for accuracy, the passenger is to select for options in terms of equipments, as illustrated in figure. 5 .

If it comes to a situation that a passenger has failed to fill in the necessary personal data, the system will not allow for him or her to make a further step. Each of the passengers must download his or her travel document (passport or ID card). In case when none of the passengers have been selected for the check-in, the system will present an error message. After a passenger has been selected for the check-in, it is possible to choose from the additional services. Each of the passengers is allowed to choose these services independently even without regard to the fact that a whole group is being checked-in simultaneously.

The next part is very important for the passengers. He or she may chose a seat, which has been allocated him or her automatically, or he or she can choose the which suit him or her best (see Fig. 6). Orange icon marks "my seat". Blue icons mark the seat not occupied and green ones those already occupied. If the passenger will not decide on the seat, he or she press the red button "Not, thanks" and he or she is automatically allocated a seat by the system.
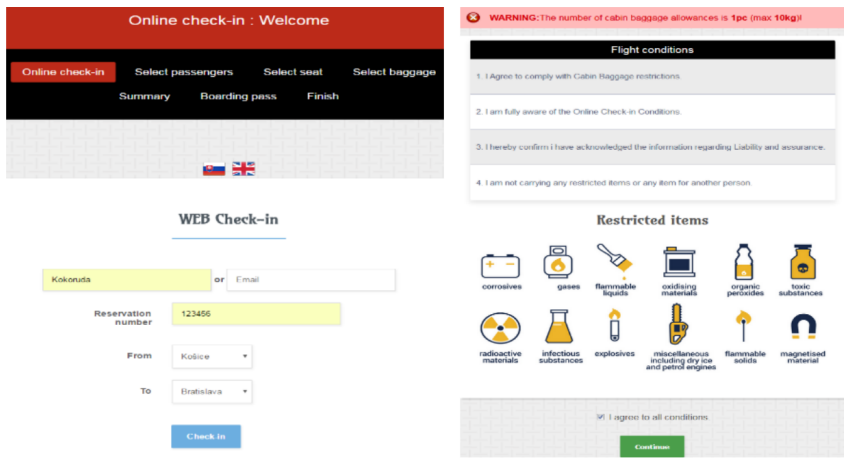

Figure 4. Initial screen of the online check-in and confirming the conditions of flight

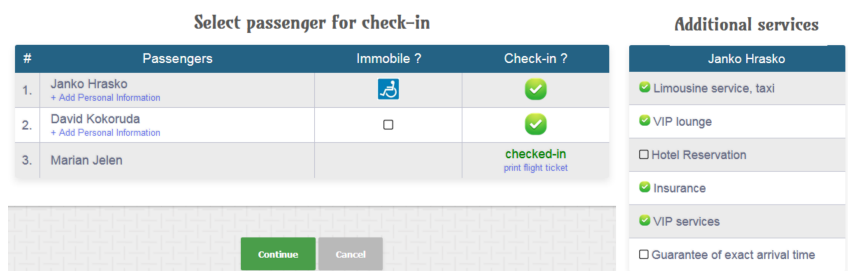

Figure 5. Selection ov passengers in the online check-in and choice from the options of additional service (on the right) 


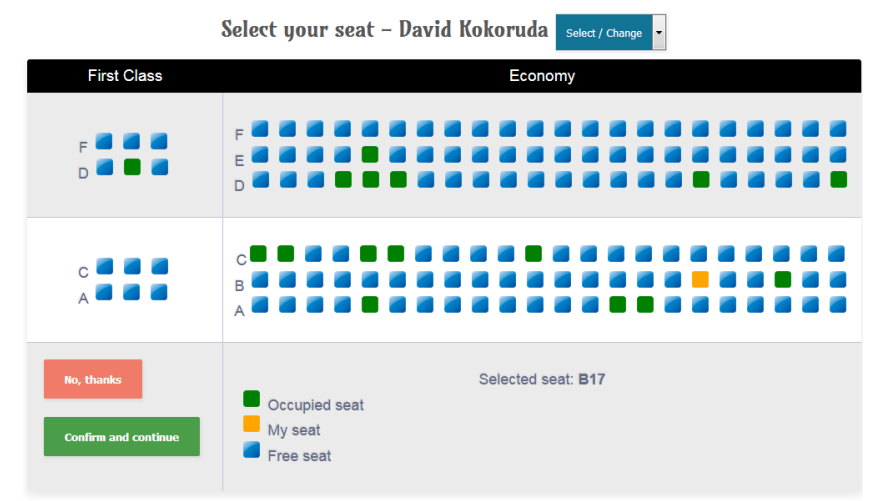

Figure 6. Choosing the appropriate seat

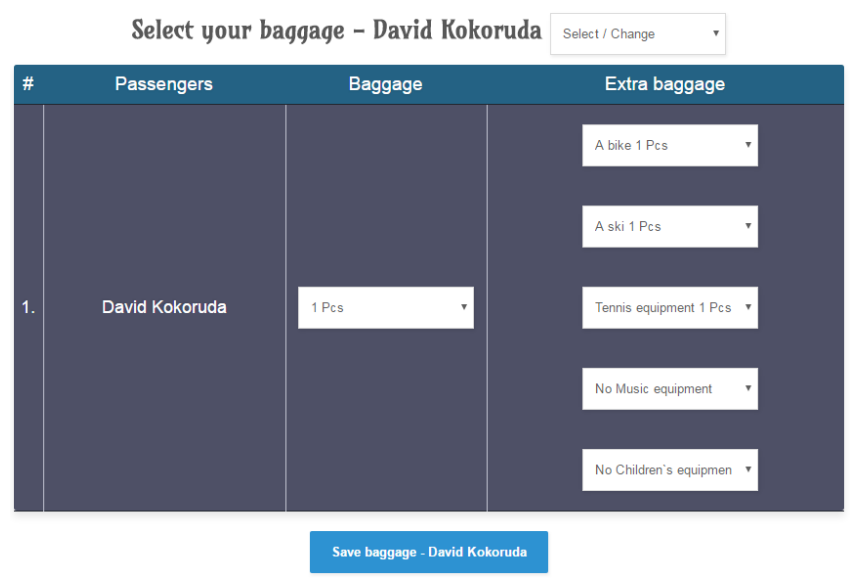

Figure 7. Choosing the appropriate baggage

In the next step the traveler is choosing from baggage options - classical or extra baggage (bike, ski, tennis equipment, music instrument, children's equipment) as seen in figure 7.

There follows a detailed description (summary) of the journey and final approval of the check-in process. Then the handling process has arrived at its end and cannot be changed. If the check-in is run without problems, the result is a generated Boarding-pass (see Fig. 8) that can be printed out directly at home or send to mobile phone as an SMS or to the e-mail address. Thus, the check-in process is considered completed and the passenger status will switched over to status Checked.

\section{Conclusion}

Intense development in the field of information systems and the deeply wedded development of services in air transportation is resulting in the hitherto unseen demand for Internet technology to satisfy the needs for the widening spectra of services offered by aviation companies. Those, who made no use of classical forms of check-ins at the airport have moved into the field of Internet. It is the Internet-based (online) handling of passengers that has become more and more popular. Air carriers spend

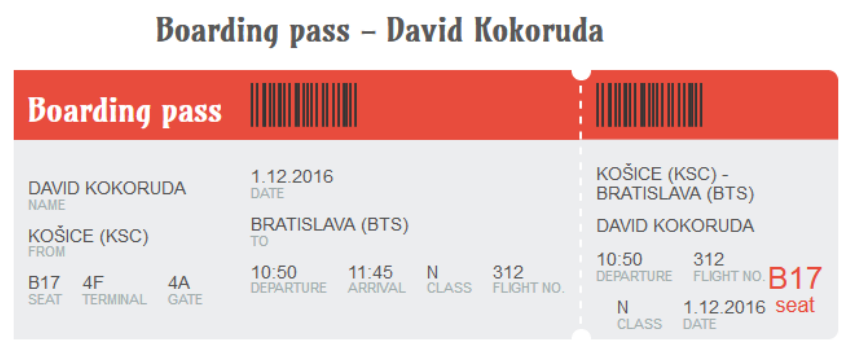

Figure 8. The Boarding-pass generated as a result

huge amounts of financial means to develop such systems, but none of the systems is completely perfect and need not necessarily meet passenger requirements.Therefore, our priority has become to participate in this trend and develop a suitable solution for increasing the efficiency of the passenger handling process. A system that would meet all the criteria for successful passenger handling and integrate the best functions making it more comfortable in via the the online process.

The implemented process can also be used in the educational process at the Faculty of Aeronautics, Technical University Košice. In the future check-in might be fully automated free of contacts between the passenger and the aviation staff. The first step along with this trend is an automated check-in as the most popular form of passenger handling. The Boarding pass is then sent to the passenger in via an e-mail, to his or her mobile phone, or can be obtained at an airport kiosk or check-in counter. Consequently, expectations for the future are about even higher level of automation and even faster check-in process. All that could be achieved by making good use of the smart phones, or smart watches, which could enable identification of the passengers from the very moment they arrive in the airport. Theses information can be then automatically sent to a kiosk, where the passenger is handed over the boarding pass.

\section{Acknowledgments}

This work was supported by the Slovak Research and Development Agency under the contract No. APVV-150527 - "New generation of departure control system for airports". The authors would like to thank the project management and colleagues for support and valuable questions, remarks and suggestions.

\section{References}

[1] L. Kerner. Provozní aspekty letišt [Operational Aspects of Airports]. CTU Publishing House, Prague, 2003. ISBN 80-01-02841-0. [In Czech].

[2] J. Sabatová, J. Galanda, F. Adamčík, M. Jezný, and R. Šulej. Modern trends in airport self check-in 
kiosks. MAD - Magazine of Aviation Development, 4 (20):10-15, Oct 2016. doi: 10.14311/mad.2016.20.02.

[3] D. Kokoruda. Online Check-in v leteckej preprave cestujúcich [Online Check-in in Passenger Air Transport]. Diploma thesis, 1999. [In Slovak]. 